\title{
Evaluation of the WRF Weather Forecasts over the Southern Region of Brazil
}

\author{
Luana Ribeiro Macedo ${ }^{*}$, João Luiz Martins Basso², Yoshihiro Yamasaki² \\ ${ }^{1}$ Atmospheric Sciences, Geophysics and Astronomy Institute, University of São Paulo, São Paulo, Brazil \\ ${ }^{2}$ Faculty of Meteorology, Federal University of Pelotas, Rio Grande do Sul, Brazil \\ Email: "lumeteorologia@gmail.com
}

Received 5 November 2015; accepted 28 March 2016; published 31 March 2016

Copyright (C) 2016 by authors and Scientific Research Publishing Inc.

This work is licensed under the Creative Commons Attribution International License (CC BY).

http://creativecommons.org/licenses/by/4.0/

(c) (i) Open Access

\begin{abstract}
The data assimilation technique, known as 3DVAR, of the WRF mesoscale modeling system has been used in order to perform the impact analysis of meteorological data assimilation in the weather forecasts over the Rio Grande do Sul State in Brazil. The consistency of the data assimilation has been analyzed by investigating and evaluating the model forecast results processed with and without data assimilations. Two different procedures of data assimilation have been conducted to perform the study. The forecasts of the accumulated rainfall model variable, spatially plotted over the model integration domains, have been compared and validated against the Tropical Rain Measuring Mission (TRMM) satellite based data, as well as with the Canguçu city meteorological radar reflectivity data. The comparison has been made considering the total amount of the accumulated rainfall predicted by the model against the automatic weather station data and most of the conducted processing presented compatible results. It has also been observed that, the inclusion of assimilated data enabled an improvement in the intensity as well as in the location of the main convective cell. The radar reflectivity field showed a significant performance in all processed experiments with data assimilation. However, for some regions, more significant obtained results have been shown to be the case in which the spectral radiances were assimilated, as compared with the case in which the spectral radiances were not included. The evaluation of the vertical atmospheric profiles of temperature and dew point temperature showed only a small impact of data assimilation. However, both simulations coherently presented the two vertical profiles, when compared with the observed profiles. In short, the study shows that, although the forecasts presented some inconsistencies in the evaluated results, the 3DVAR assimilation improves significantly the forecasting of the Weather WRF model.
\end{abstract}

\section{Keywords}

Data Assimilation, 3DVAR, Tropical Rainfall Measuring Mission, WRF, Radiances

\footnotetext{
"Corresponding author.
} 


\section{Introduction}

Atmospheric convective activities may be intensified by the topography and local wind circulations that, under favorable environmental conditions can cause intense precipitation and severe weather conditions in a time span of few hours [1]. Atmospheric condition changes that may occur in a short time period, combined with the great variability of the precipitation variable in time and space, contribute to stickling on its forecast by mesoscale models.

The rainfall data measurements can be locally made at observational points, through collections in rainfall networks. They can also be done or indirectly retrieved based on inference techniques using measurements made by remote sensors and sounders, such as surface microwave sounders, radar and satellites onboard instruments. Remote sensing provides, with no doubt, the most appropriate tools to get rainfall estimates over large areas especially over inhospitable regions and vast oceans.

It is worth to emphasize that advancement of space technologies in the area of remote sensing has been providing high spatial resolution satellite data to major meteorological operational centers. This fact, associated with the numerical model assimilation techniques has been causing a great positive impact on forecasting of the numerical models. According to [2], the main approaches developed in the modeling area comprise the assimilation of data retrieved by spectral radiances, as well as by assimilating the proper spectral radiance. In retrievals procedures, the assimilation is done with a set of geophysical parameters such as vertical profiles of temperature and humidity, which are commonly used in the data assimilation system (DAS). The geophysical parameters retrieval procedures, from satellite spectral radiances data, involve a highly non-linear estimation process, in the solution of the ill-posed problem and require a priori information or support data. The best alternative is to use the satellite radiances data directly in the DAS. This approach is presented as an improvement in satellite data assimilation and assimilations are directly made in the radiation physics of numerical models. In this case, considering that spectral radiances errors are independent, stationary and uncorrelated with the forecast, they are more justified than the assimilation of data retrieved. One way to overcome the problems of radiance data assimilation is to use the variational methods 3DVAR or 4DVAR (Four-Dimensional Variational) [3]. The procedures have been the fundamentals resources used by major operational meteorological centers, as described by [4] and [5]. However, this technique involves the use of the radiative transfer scheme as the observation operator, which interpolates the data of the observations to the physical space of the numerical model.

Recently, the WRF model has been used for heavy rainfall forecasts by the scientific community in Brazil. [6] showed that the WRF model identifies very consistently the observed maximum core of precipitation convective cell, for a period of 24 hours, with forecasting values quite compatible to those observations in the Southern Brazil. In the present work the evaluation is made to present the impacts of spectral radiances and meteorological observations data assimilations, made with the WRF/3DVAR modeling system. The main results are presented for a case of heavy rainfall occurring in the city of Porto Alegre-RS. This event, in a six-hour period, showed the occurrence of rainfall of about $56 \mathrm{~mm}$ - equivalent to $50 \%$ of the monthly historical average-which, according to the INMET, is $100.10 \mathrm{~mm}$. The rainfall reached its highest intensity between the 20:00 $\mathrm{h}$ and 22:00 h time period of January 7, 2013. During this time period the automatic station of the INMET registered 38.0 $\mathrm{mm}$ of accumulated rainfall. The large volume of rainfall caused and generated great inconvenience to the population; various points of flooding in the city, as recorded by the Public Company of Transportation and Circulation (EPTC); and the interruption of electricity supply in a large area of the city.

\section{Material and Methods}

The region of study encompasses the entire Rio Grande do Sul State (RS-Brazil), covering the area located below the Tropic of Capricorn, between latitudes $27^{\circ} 03^{\prime} 42^{\prime \prime S}$ and $33^{\circ} 45^{\prime} 09^{\prime \prime S}$, and longitudes $57^{\circ} 40^{\prime} 57^{\prime \prime} \mathrm{W}$ and $33^{\circ} 45^{\prime} 41^{\prime \prime W}$; with the main focus over the Metropolitan Region of Porto Alegre city, as illustrated in Figure 1. A severe weather event analysis has been made using high resolution infrared channel satellite image of the GOES-13; surface meteorological synoptic charts of the Navy Hydrographic Center; analysis data from the GFS (Global Forecast System)/NCEP (National Center for Environmental Prediction) model; TRMM (Tropical Rainfall Measuring Mission) satellite data and the simulations forecasts results of the WRF and WRFDA modeling system. The WRF model has been integrated, taking the 0.5 degree space resolution analysis and forecasting of the GFS global model, with spatial resolution of 0.5 degrees as initial and boundary conditions. The investigations have been made with 3DVAR assimilation of the data including the surface meteorological variables data collected by the INMET (National Institute of Meteorology) automatic surface stations network; 


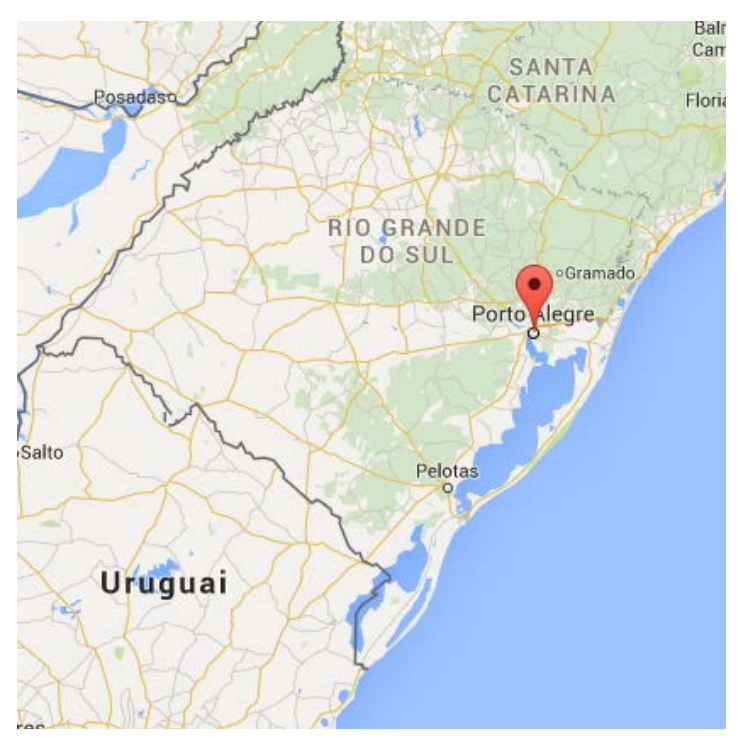

Figure 1. Area of study, focusing the RMPA.

upper air radio-soundings; buoys and ship (ship) data; wind satellite data (SATOB); metar and synop data. The spectral radiances AMSU-A (Advanced Microwave Sounding Unit-A); AMSU-B (Advanced Microwave Sounding Unit-B); HIRS-3 (High Resolution Infrared Sounder-3) and HIRS-4 (High Resolution Infrared Sounder-4) satellite data have also been used in the assimilation processes.

\subsection{Data Assimilation System}

The Data Assimilation System produces an estimate of the atmospheric conditions at a time given instance referred as analysis. It is obtained throughout all available information of the atmospheric state from earlier observations and forecasts data-which are the first approach. It also incorporates the information regarding their errors and the laws of atmospheric physics [7].

The WRF system integrates a set of variational data assimilation software called WRFDA, and incorporates the 3DVAR/4DVAR modules. In the present conducted research it is used the 3DVAR module. The variational data assimilation technique makes an adjustment to the meteorological variables, to minimize the difference between the adjusted and the observed fields, throughout an iterative process. This is made considering the physical assumptions as restrictions to the atmospheric flow, to obtain a dynamic equilibrium. The minimization procedure is performed through the cost function $(J)$ as described by [8] and is based on Bayesian probability theory. Mathematically the function is expressed as:

$$
J(x)=\frac{1}{2}\left(x-x_{b}\right)^{\mathrm{T}} B^{-1}\left(x-x_{b}\right)+\frac{1}{2}\left(y_{0}-H\left(x_{b}\right)\right)^{\mathrm{T}} R^{-1}\left(y_{0}-H\left(x_{b}\right)\right)
$$

where $x$ represents the observation, $x_{b}$ the background field (or support field); $y_{0}$ the initial estimate; $H$ the observation operator; $B$ the covariance matrix error estimate, and $R$ is the covariance matrix of the observation errors. The covariance matrix error estimate $B$ is the most important part of the variational analysis method, in order to determine the rate of impact and the increments distribution ratios of the analysis.

Figure 2 presents a general flowchart summary of the 3DVAR system used by WRF. The prediction support or background field results from the model product itself, integrated for a short term period. The preprocessor provides the observations $y_{0}$, to be ingested by 3DVAR. The 3DVAR_OBSPROC module has distinct basic functions. It reads the observational data, in a format known as LITTLE-R [9]; performs the spatial and temporal verification of the observed data; get the heights, the observations in pressure coordinates; eliminates duplicated data and select the observations, which have different values at different times. In addition, it estimates the errors of each observation and produces data in a format suitable for further processing of WRF.

The statistics of the support error covariances are used in the cost function of 3DVAR to weight the errors associated with the supporting field. The assimilation system filters the support structures and observation, 


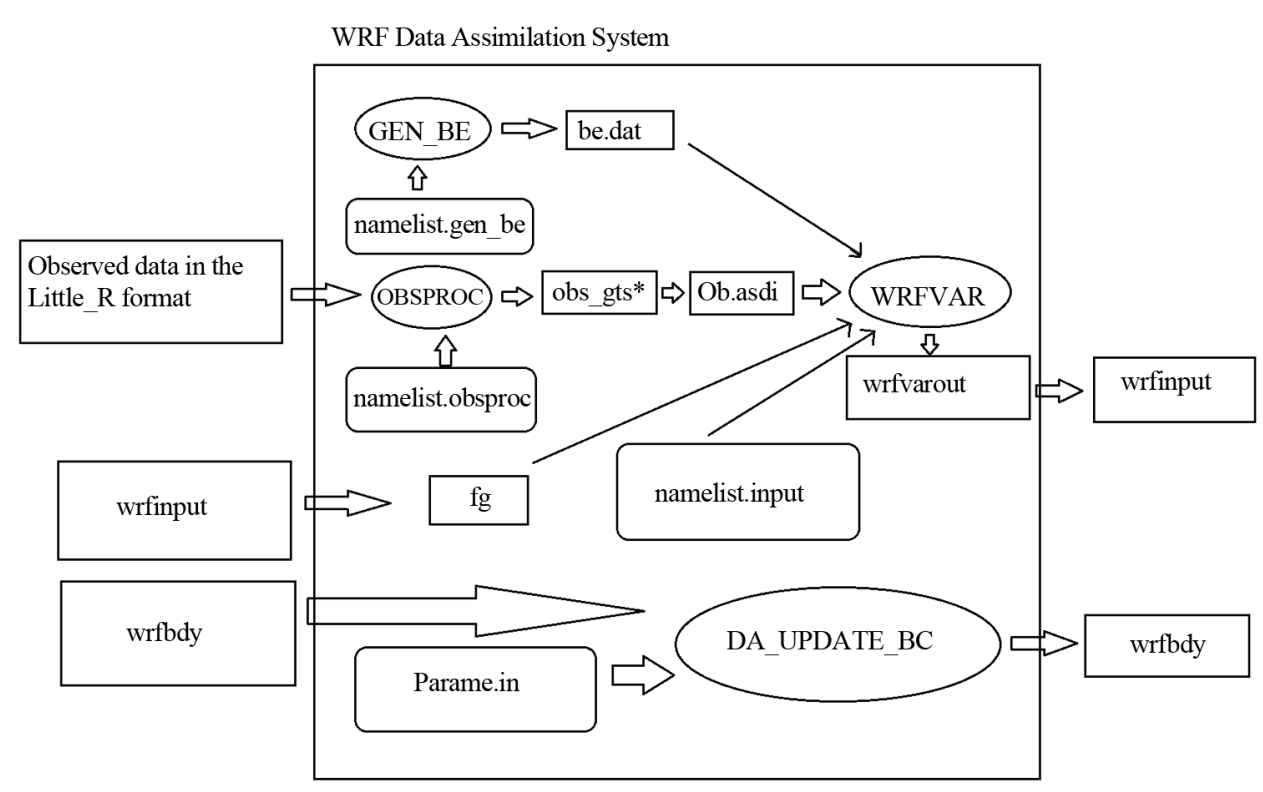

Figure 2. 3DVAR system fluxogram. [11].

which have high relative errors to those known more correctly. In fact, the mistakes of support fields are synoptically dependents, in other words, vary from day to day depending on weather conditions and situation [10]. After verifying that all files are consistent, WRFVAR is processed generating an output, wrfvarout, which is used as wrfinput. Thus, it produces a new initial condition (IC), with assimilated data, for the integration of the WRF model. The increments of the analysis have been checked using plotting of some meteorological fields, to explore the impact of data assimilation. This process can also be done using procedures which determine the difference between IC with and without data assimilation. The new CI and CF (boundary condition), generated by the WRFVAR system, are used by WRF model to make forecasts with data assimilation.

\subsection{Model Configuration and Processing}

The non-hydrostatic mesoscale atmospheric model WRF has been configured with four nested domains-covering the area of integration depicted in Figure 3. The parameterizations used in the model are presented in Table 1. The horizontal space resolution; the number of horizontal grid points; as well as the vertical number of ETA levels and the top pressure level established to the model are shown in Table 2. The numerical integrations have been performed for 48 hours. The start time has been set aside for each simulated event and 27 seconds time step has been used for most of the processed cases. It is noteworthy that the small time step was necessary to avoid the CFL [12] problem, proved as critical in the event of very heavy rainfall. The simulations were performed on a cluster with a total of 36 parallel processors.

Initially the model processing has been performed using, as initial and boundary conditions, the numerical predictions of the GFS/NCEP model data, which will henceforth referred as WRF. In sequence, the model processing has been performed with the assimilation of: SYNOP data types, METAR, TEMP, SATOB, SHIP, BUOY, PILOT, AIREP, RADAR and automatic weather stations surface of the INMET network-which will be henceforth referred to as WRFVAR_1. The third types of processing, hereinafter referred as WRFVAR_2, were similar to the second one, except that they include the assimilation of satellite spectral radiance data.

\subsection{Weather Meteorological Radar}

The Doppler weather radar data used has been collected by the station installed at Canguçu-RS city, located at coordinates $31^{\circ} 24^{\prime} 14 " \mathrm{~S}$ and $52^{\circ} 42^{\prime} 06^{\prime \prime} \mathrm{W}$ and 466.57 meters above mean sea level. It operates in S band (2.7 to 3 $\mathrm{GHz}$ ), with a wavelength of $10 \mathrm{~cm}$, operating with microwave beam angle of approximately $2^{\circ}$. This radar makes the scanning every 15 minutes and operates 24 hours a day. Figure 4 shows the radar coverage for a range of $400 \mathrm{~km}$. It is operated by the Department of Airspace Control (DECEA) and under an agreement with 


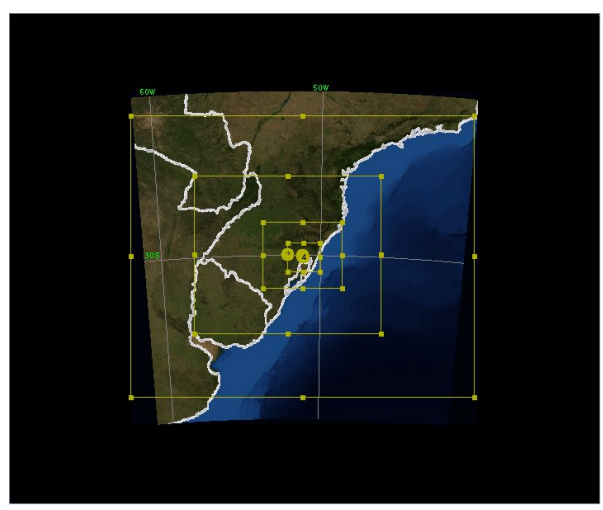

Figure 3. WRF model integration domains.

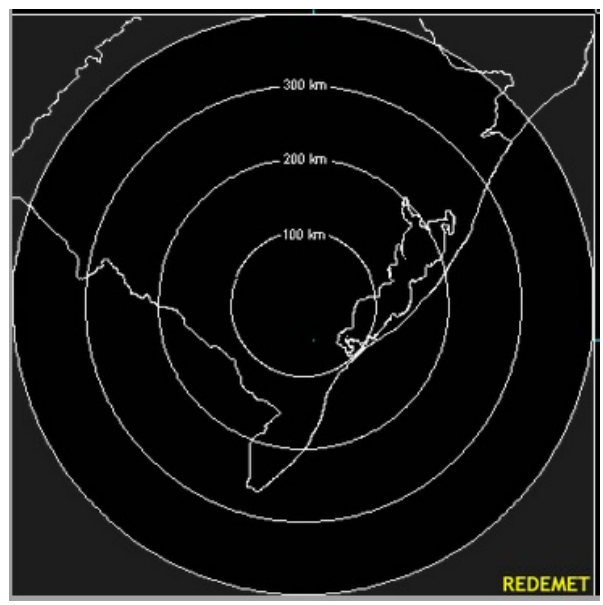

Figure 4. Canguçu radar coverage area for a beam of $400 \mathrm{~km}$.

Table 1. Parameterizations utilized in the processing.

\begin{tabular}{|c|c|c|c|c|}
\hline & \multicolumn{4}{|c|}{ Parameterizations } \\
\hline & D1 & D2 & D3 & D4 \\
\hline Microphysics & Thompson et al. & Thompson et al. & Thompson et al. & Thompson et al. \\
\hline Convection & Kain-Fritsch & - & - & - \\
\hline Radiation LW & RRTM & RRTM & RRTM & RRTM \\
\hline Radiation SW & Dudhia & Dudhia & Dudhia & Dudhia \\
\hline PBL & Mellor-Yamada-Janjic & Mellor-Yamada-Janjic & Mellor-Yamada-Janjic & Mellor-Yamada-Janjic \\
\hline
\end{tabular}

Table 2. WRF configuration general characteristics.

\begin{tabular}{ccccc}
\hline General Simulation Characteristics & \multicolumn{3}{c}{ Horizontal Grid Resolution } \\
\cline { 2 - 5 } & $\begin{array}{c}\mathrm{D} 1 \\
(18 \mathrm{~km})\end{array}$ & $\begin{array}{c}\mathrm{D} 2 \\
(6 \mathrm{~km})\end{array}$ & $\begin{array}{c}\mathrm{D} 3 \\
(2 \mathrm{~km})\end{array}$ & $\begin{array}{c}\mathrm{D} 4 \\
(1 \mathrm{~km})\end{array}$ \\
\hline Horizontal Number of Grid Points & $115 \times 94$ & $187 \times 157$ & $238 \times 196$ & $35 \times 256$ \\
Vertical Levels & 35 & 35 & 35 & $50 \mathrm{hPa}$ \\
Model Top & $50 \mathrm{hPa}$ & $50 \mathrm{hPa}$ & $50 \mathrm{hPa}$ \\
\hline
\end{tabular}


the National Institute for Space Research (INPE) the raw radar data is processed. In the processing procedure the data are provided in CAPPI format (“Constant Altitude Plan Position Indicator"), for 15 vertical levels, from 2 $\mathrm{km}$ to $16 \mathrm{~km}$ height. The obtained CAPPI product from the radar reflectivity, are collected for each azimuth and elevation. At the end of the electronic scanning process, the three-dimensional radar data volume is obtained; providing the entire vertical profile of radar reflectivity, in $\mathrm{dBz}$, within the coverage area. After setting the height levels the interpolation is made with information, contained in each of elevations of the PPI ("Plan Position Indicator"), thus forming a reflectivity field for a constant altitude plan. As the horizontal resolution of the radar data ( $1 \mathrm{~km}$ by $1 \mathrm{~km}$ ) is greater than the first 3 domains of the model, they have been properly processed, to get displays compatible with the model space resolution.

\subsection{Satellite Data}

The satellite observations are considered as primary sources of information for NWP models. Currently the satellites products have been proved as quite satisfactory to meteorology, especially due to the associated technological instruments advances as well as pre-processing systems; besides for being the major data source of meteorological data products especially for the nowadays model assimilation systems. As an example it is mentioned the METOP satellite, on board of which allows it to provide high spectral resolution sensor data with thousands of spectral channels. These sensors have been allowing the temperature and humidity profiles retrievals with very high accuracies. In the present presentation and development it has been used the AMSU-A, AMSU-B, MHS, HIRS-3, HIRS-4, instruments data.

\section{Results and Discussion}

The high space resolution GOES13 infrared channel satellite image sequence, presented in Figure 5, shows a squall line drifting toward the southernmost state of Brazil during the dusk and evening of January 07, 2013. The image sequence also presents a convective system intensifying in a short time period and rapidly reaching the state of Rio Grande do Sul, including the metropolitan area of Porto Alegre capital city (MAPA).
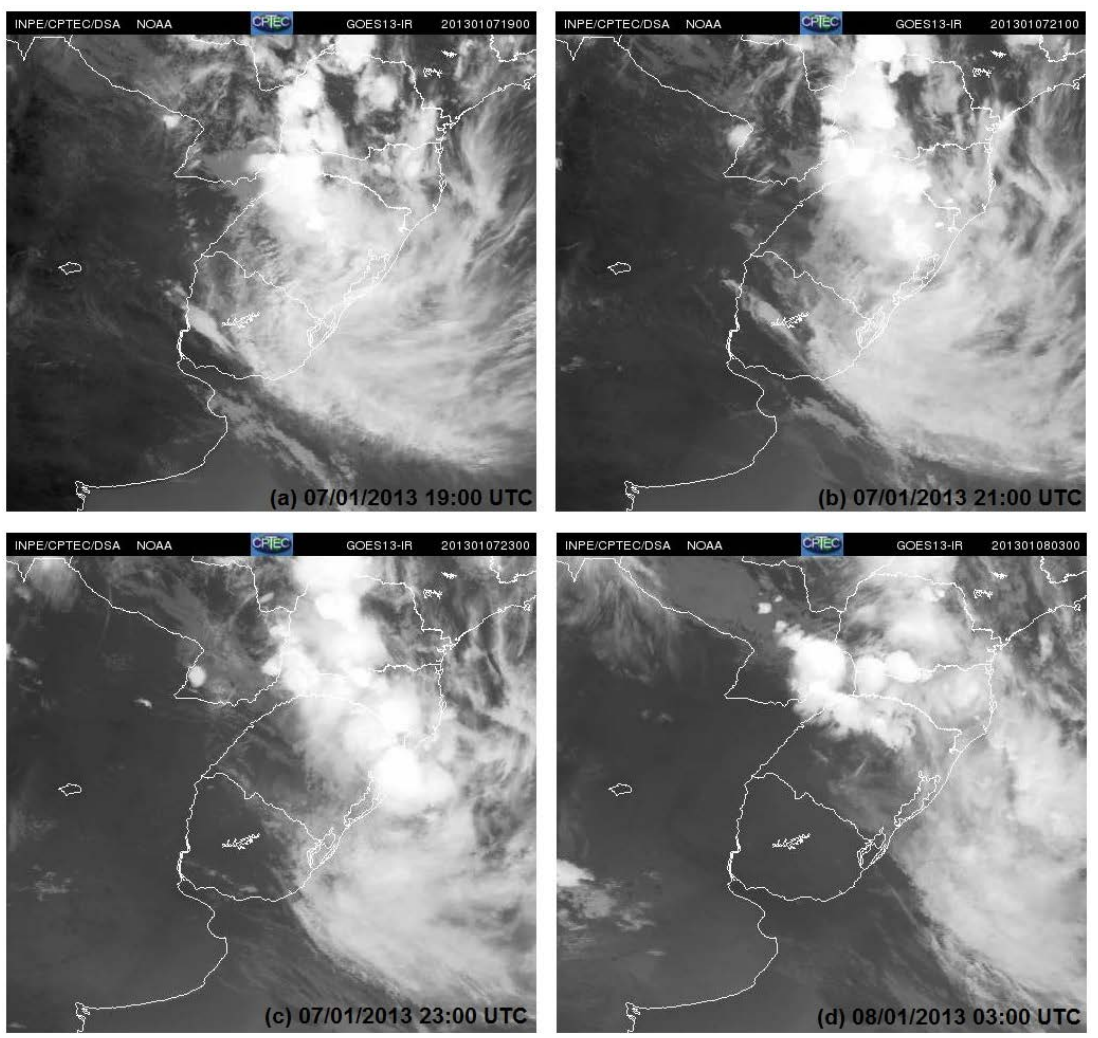

Figure 5. GOES-13 IR satellite image sequence. 
The divergence and the wind magnitude at 250 hPa level fields are shown in Figure 6 and Figure 7, respectively. In Figure 6, a strong diffluent flow can be seen over the North, Midwest, Southeast and Northeast Brazil, in addition to northern Argentina, Paraguay and the southern part of Brazil. This diffluent flow intensified the lifting of the air column of the lower layers of the troposphere. Also, in the divergence field, it is possible to observe a trough, whose axis is positioned in the northwest/southeast direction, extending over the north of Chile to the region near the province of Buenos Aires, Argentina. The forefront of this trough is bypassed by a branch of Subtropical Jet (JST), as shown in Figure 7. The JST presence, with the trough, contributed to the diffluent flow intensification in the northern Argentina, Uruguay, Paraguay and southern Rio Grande do Sul, favoring the intensification of convection on these areas, as shown in satellite images.

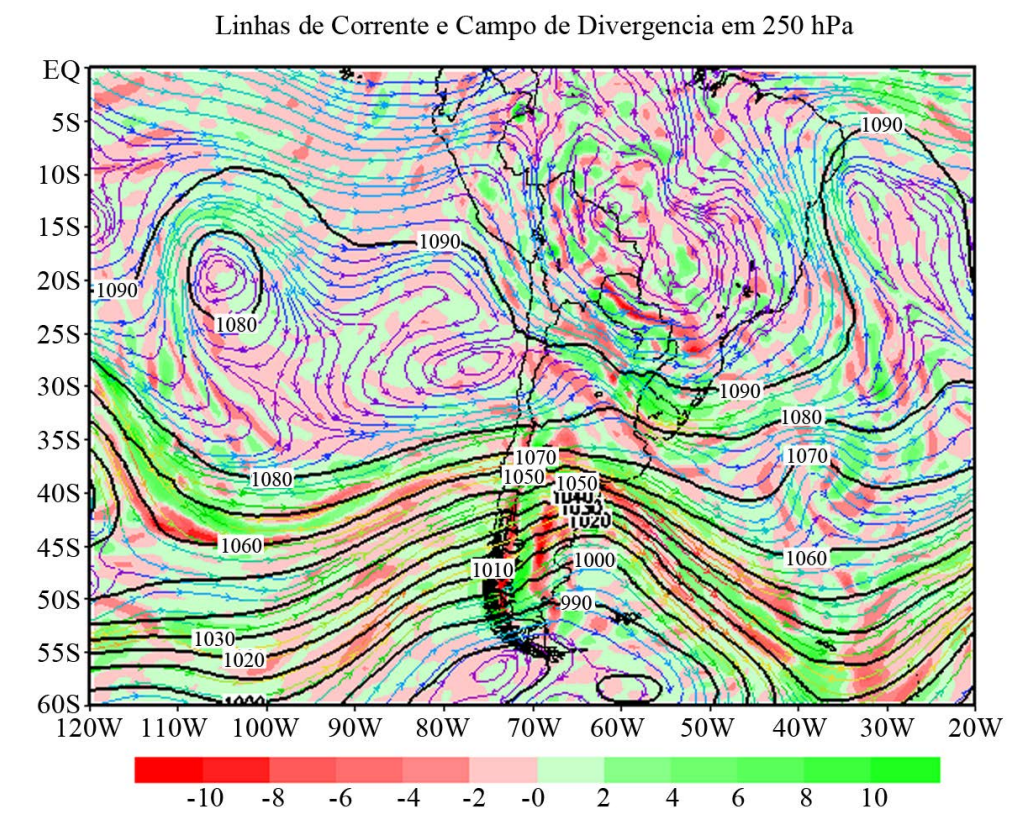

Figure 6. Streamlines and divergence field at $250 \mathrm{hPa}$ for 12 UTC on January $7^{\text {th. }}$.

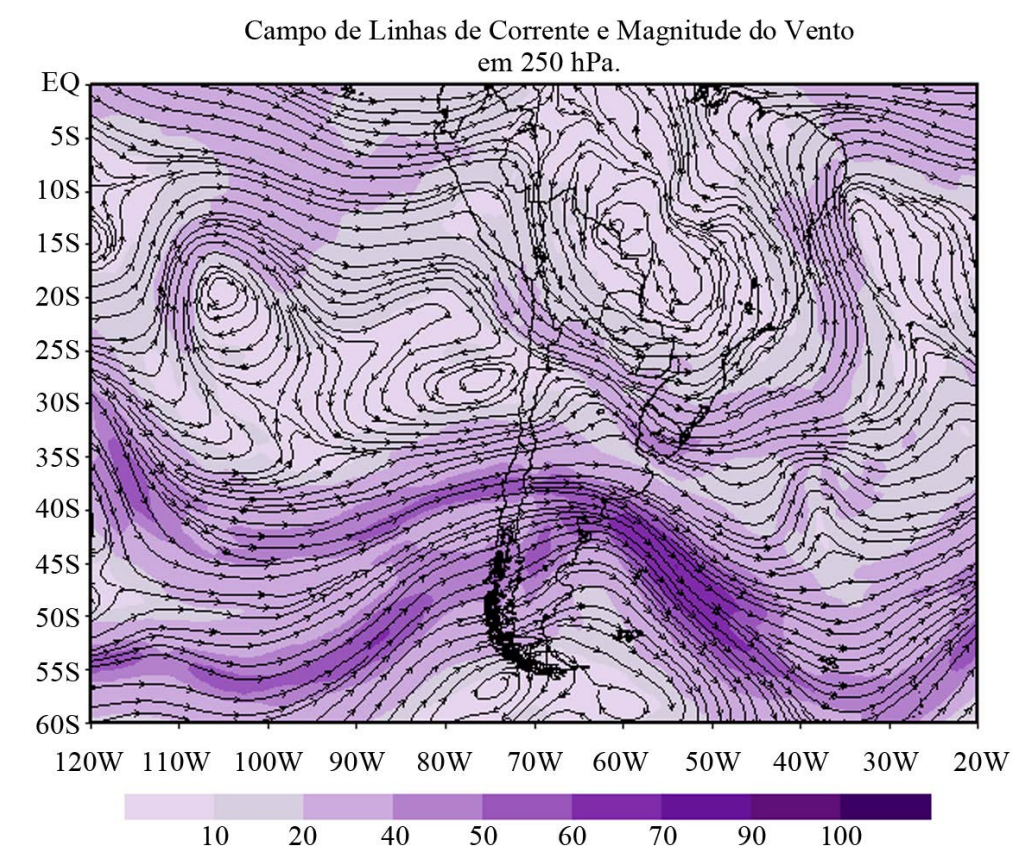

Figure 7. Streamlines and wind magnitude at $250 \mathrm{hPa}$ for 12 UTC on January $7^{\text {th }}$. 
The Figure 8 shows the relative vorticity and streamlines at $500 \mathrm{hPa}$; where an anticyclone can be observed centered near 20S/52W. This subsidence causes a system, which hinders the formation and vertical development of clouds. Note, in addition, the presence of a trough extending from Chile to Buenos Aires. The East of this trough is observed a negative vorticity, which acts also over large part of the Rio Grande do Sul state, thus indicating severe storms in the higher levels. The relative humidity, temperature and power lines are represented at $850 \mathrm{hPa}$ in Figure 9. This figure also shows a part of the anticyclonic circulation in the Atlantic, near 31S/25W, this movement acts on large part of the continent north of 40S, and influences the performance of the anticyclone Subtropical surface. Note the presence of low level jets (LLJ) extending from the southern state of Acre to northern Argentina. These jets intensify the advection of warm and moist mass of lower latitudes in the Southern region of Brazil, Uruguay and northern Argentina, also intensifying the standard thermodynamic on these areas. This behavior associated with the trough of the middle and upper troposphere, and JST in altitude favor the instability of these areas.

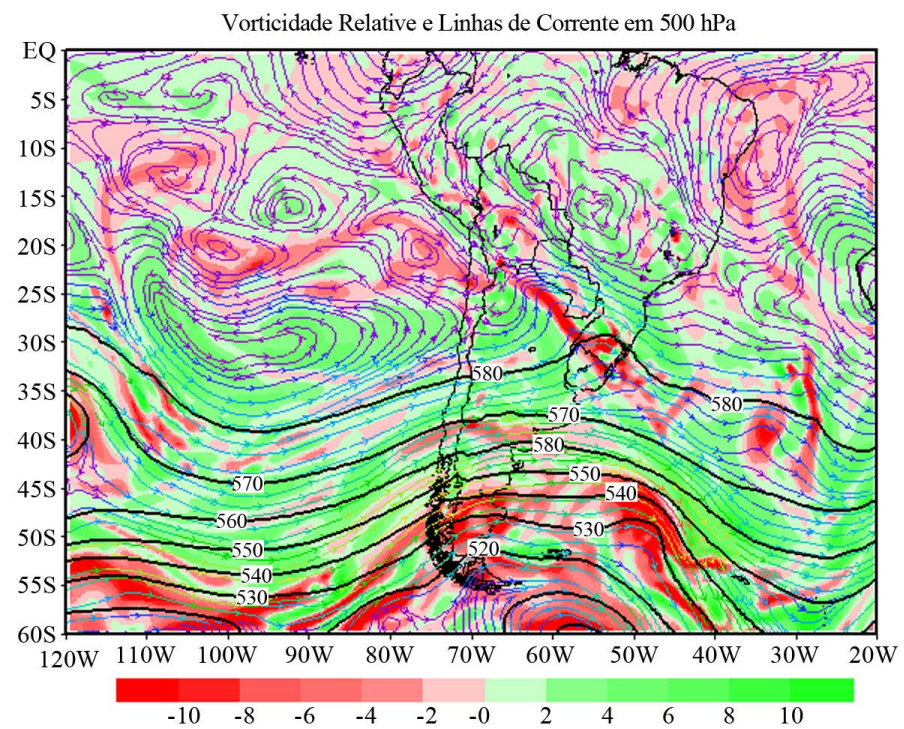

Figure 8. Relative vorticity and streamlines field at $500 \mathrm{hPa}$ for 12 UTC on January $7^{\text {th }}$.

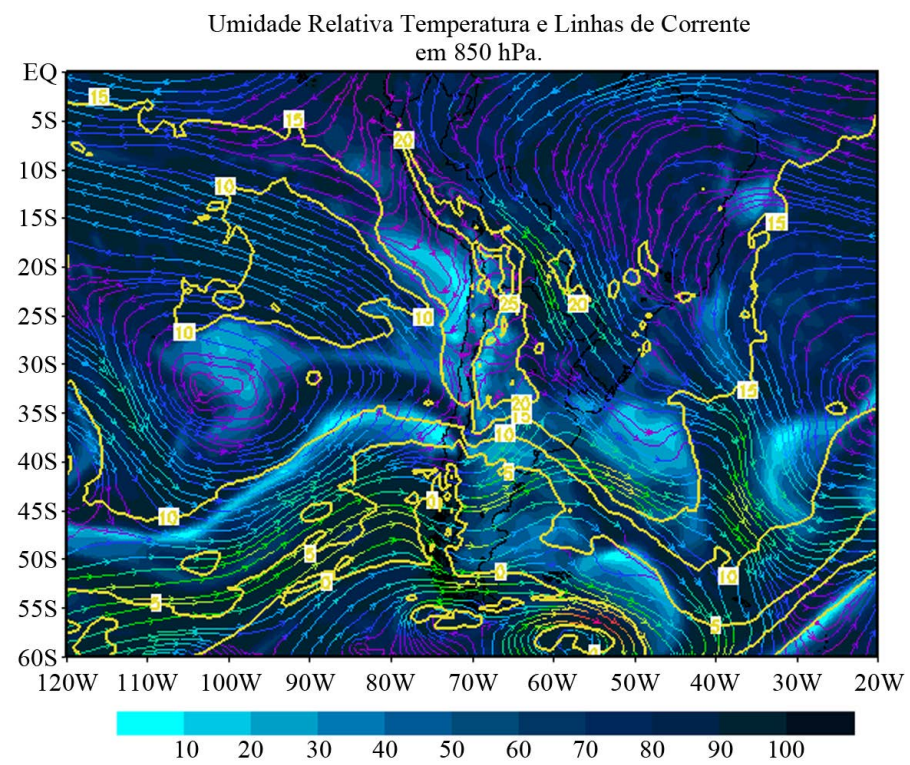

Figure 9. Relative humidity, temperature and streamlines field at $850 \mathrm{hPa}$ for 12 UTC on January $7^{\text {th }}$. 
The impact of model data assimilation over the precipitation fields are shown in the results of the three simulations carried out (WRF without data assimilation, and WRFVAR_1 WRFVAR_2 with data assimilation) in Figures 10(a)-(c) the accumulated precipitation fields for 6 hours period-including the period of the 18:00 Z of the January 7 to $00 \mathrm{Z}$ of January 8, 2013. According to the automatic meteorological data network stations of the National Institute of Meteorology (INMET), the city of Porto Alegre accumulated, during this period, around 56 $\mathrm{mm}$ of rainfall. Analyzing the three processing results, it has been possible to notice that all processing showed uniform performance, with precipitation cores varying from $40 \mathrm{~mm}$ to $80 \mathrm{~mm}$. For the precipitation cores between $80 \mathrm{~mm}$ and $160 \mathrm{~mm}$ there were a time lag in the system, while the processing WRFVAR_1 (Figure 10(b)) shows the cell Northwest the WRF processing (Figure 10) and WRFVAR_2 (Figure 10(c)) indicate the same precipitation cell over the center of the state. The WRFVAR_2 simulation was unable to detect the core of rainfall between $140 \mathrm{~mm}$ and $160 \mathrm{~mm}$ as provided by other processing, while the simulation of the WRF did not detect the cores of precipitation between $80 \mathrm{~mm}$ and $100 \mathrm{~mm}$ over the western part of the state, as detected by the simulations with data assimilation (as circled in Figures 10(b)-(c)). The analysis over a single local point of the state, closest to the observed precipitation has been given by the WRFVAR_1 simulation, with values around $45 \mathrm{~mm}$.

The accumulated rainfall fields for the 24-hour period were also evaluated, using as a basis for comparison the estimated TRMM data (Figure 11). The forecasts with distinct initial conditions for January $7^{\text {th }}$ at 12 UTC to January $8^{\text {th }}$ at 12 UTC are shown in Figures 12(a)-(c). This figure show that both processes (WRFVAR_1 and WRFVAR_2) have presented an increase in the intensity of precipitation cores in relation to prognosis without data assimilation shown in Figure 12(a); thus contrasting to the work of [13], where the results showed that the data assimilation technique 3DVAR not performed well over the intensity and location of convective cells. Both simulations forecasts compared with the TRMM data, super estimate precipitation values. This, eventually results, due to the possibly of the TRMM satellite data do not show a temporal frequency consistent with the occurrence of rainfall. The comparison between the observed reflectivity (Figure 13) and simulated (Figure 14) was done for the day January $7^{\text {th }}, 2013$ at 18:00 UTC. The values of the observed reflectivity are significant in the east/southeast and southwest of the radar range area sector. It was observed that both simulations have shown consistency with the observed reflectivity; thus opposing to [7] previous work, which assimilated radar reflectivity data using 3DVAR system with MM5 model, and found that there were no significant improvements to the simulation of the reflectivity fields. In Figure 14, there are reflectivity points consistent with what have been observed mainly near the regions of Canguçu, Bagé, Pelotas and Rio Grande, in both processing with data assimilation. The WRFVAR_1 processing presented points, closer to that observed near the city of Bagé. In the Southeast of the state, the simulations underestimated the reflectivity values when compared to the observed one. The vertical temperature (T) and dew point temperature (TD) profiles for the city of Porto Alegre have been analyzed, using skew-T thermodynamic diagram as shown in Figure 15 and Figure 16 respectively, to evaluate the WRF model ability to simulate the vertical profiles and also, to see if there are any improvement when simulations are



(a)

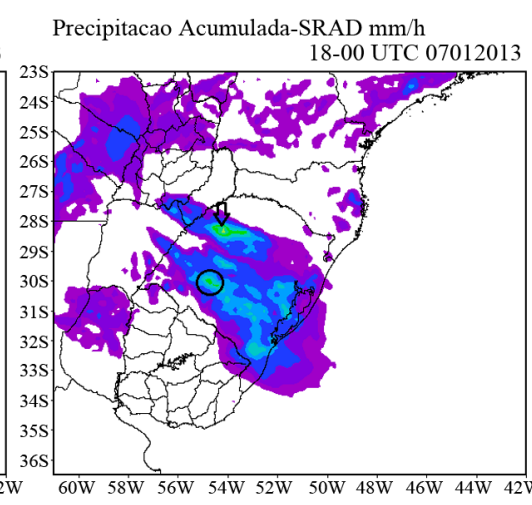

51020406080100120140160180200220

(b)

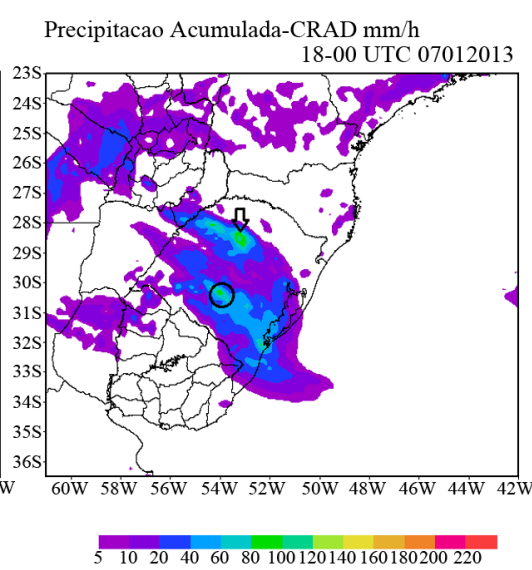

(c)

Figure 10. Accumulated rainfall in 6 hours from January $7^{\text {th }}$ at 19:00 UTC to January $8^{\text {th }}$ at 00:00 UTC for simulations with distinct data sources (a) WRF; (b) WRFVAR_1; (c) WRFVAR_2. 
Mean Precipitation - TMI mm/h - (color, $\mathrm{mm}$ )

20130107



$\begin{array}{llllllllll}0.1 & 0.2 & 0.4 & 0.8 & 1.6 & 3.2 & 6.4 & 12.8 & 25.6 & 51.6\end{array}$

Figure 11. TRMM accumulated rainfall field for the time span of 24 hours for January $7^{\text {th }}, 2013$.

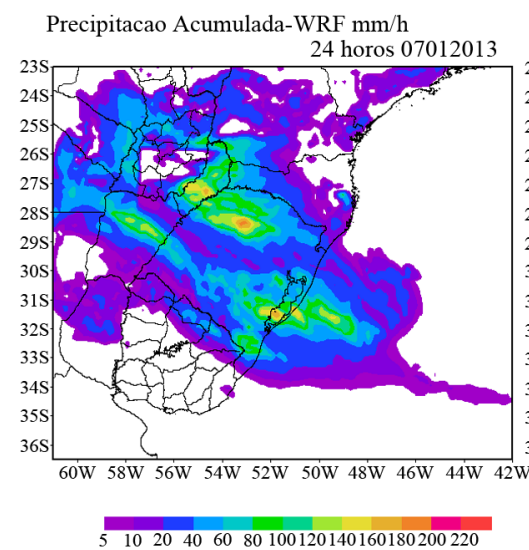

(a)

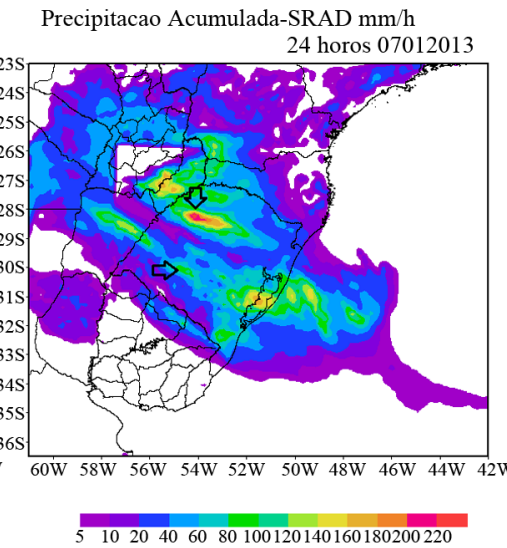

(b)

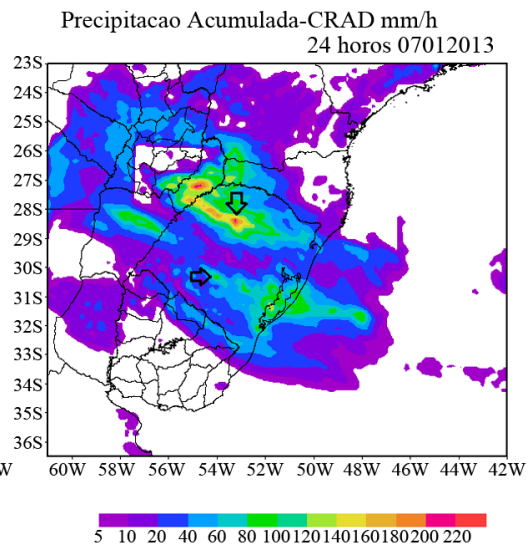

(c)

Figure 12. Accumulated rainfall in 24 hours from January $7^{\text {th }}$ at $12: 00$ UTC to January $8^{\text {th }}$ at $12: 00$ UTC for simulations with distinct data sources (a) WRF; (b) WRFVAR_1; (c) WRFVAR_2.

made with data assimilation. The comparison of the WRF simulations without, and with data assimilations of conventional observational data (WRFVAR_1) as well as of radiance data (WRFVAR_2) has been made. The simulation results for January $8^{\text {th }}, 2013$ (00:00 UTC) are shown in Figure 15. It is possible to note that the observed profile of TD presented thermal inversion level near $500 \mathrm{hPa}$ and between the $200 \mathrm{hPa}$ and $100 \mathrm{hPa}$ atmospheric layer. Note that WRF model with and without data assimilation was able to depict quite well the thermal inversions which occur between the $200 \mathrm{hPa}$ and $100 \mathrm{hPa}$ layer. The profile without data assimilation presented a small inversion near the surface and $650 \mathrm{hPa}$, which have not been presented in the observed sounding. On the other hand the profile with assimilation WRFVAR_1 case, has shown inversions near $800 \mathrm{hPa}$ and $700 \mathrm{hPa}$, which also have not been presented in the observed profile. The profiles of WRFVAR_2 radiance data 


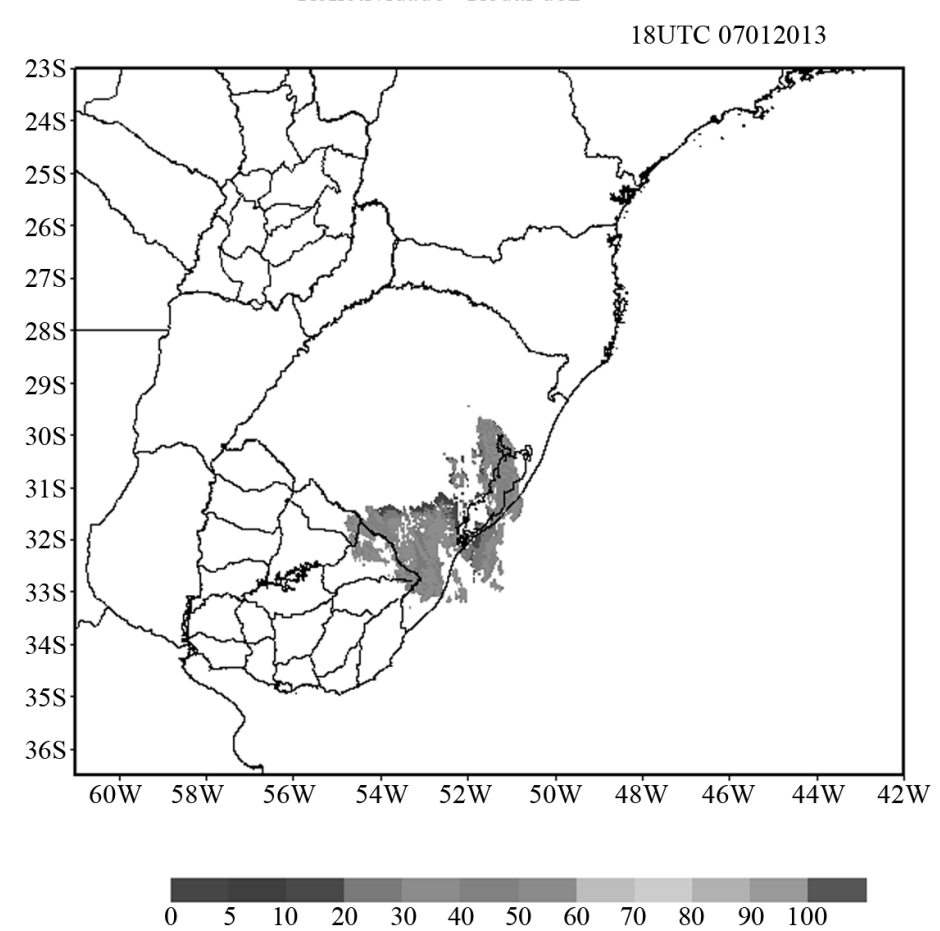

Figure 13. Canguçu radar reflectivity field for 19:00 UTC.



$\begin{array}{llllllllllll}0 & 5 & 10 & 20 & 30 & 40 & 50 & 60 & 70 & 80 & 90 & 100\end{array}$

(a)

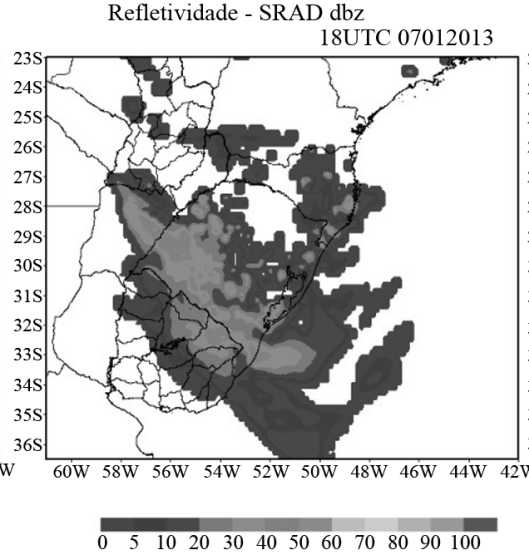

(b)

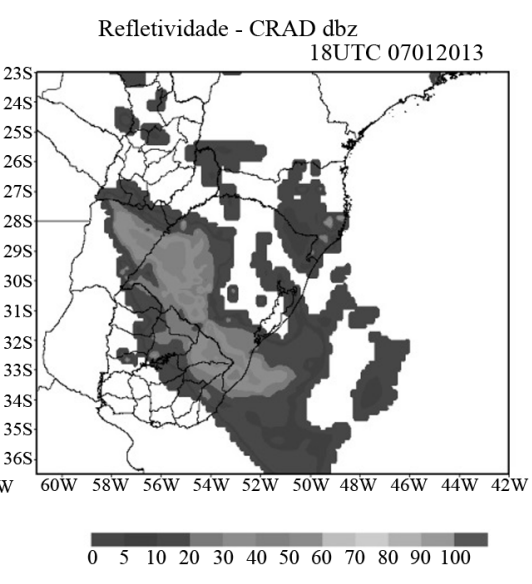

(c)

Figure 14. Reflectivity fields for January $7^{\text {th }}$ at 18:00 UTC for simulations with distinct data sources (a) WRF; (b) WRFVAR_1; (c) WRFVAR_2.

assimilation case, on the other hand, showed significant levels of inversions between $500 \mathrm{hPa}$ and $400 \mathrm{hPa}$; which are quite strong if compared with the observed values. However, its symmetry has been maintained during the development of the profile between the levels of $1000 \mathrm{hPa}$ and $600 \mathrm{hPa}$. Between the $200 \mathrm{hPa}$ and 100 hPa levels, similar values have been observed in all simulations. As shown in Figure 16, the vertical temperature profile (T) for January $8^{\text {th }}, 2013$ (00:00 UTC), presented good consistency compared to the observed profile. However, in the surface and mid-levels, the simulated WRF and WRFVAR_1 cases presented over casting, and down-casting for WRFVAR_2 processing.

In Figure 16(b), it can be inferred that the profile, with the inclusion of WRFVAR_1 data assimilation, between the layers of $700 \mathrm{hPa}$ and $500 \mathrm{hPa}$ presents results very close to the observed values. This situation, for WRFVAR_2 simulation, only occurs between the 700 and 600 hPa levels. On the other hand, the profile without 


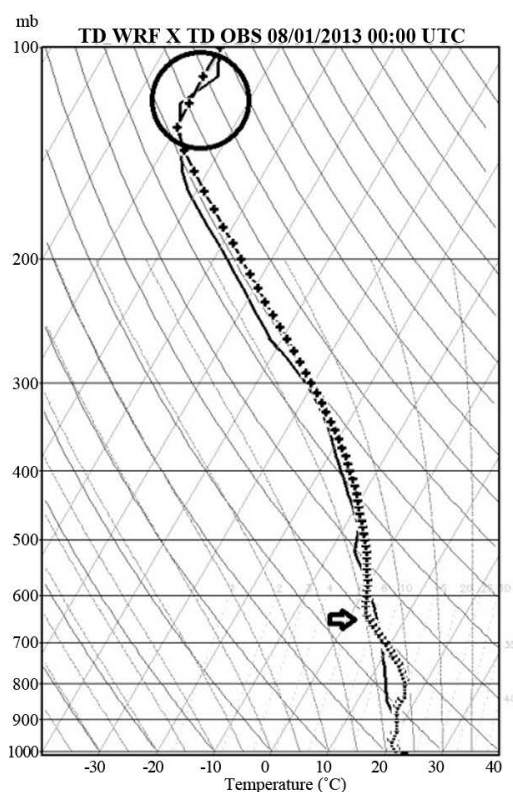

(a)

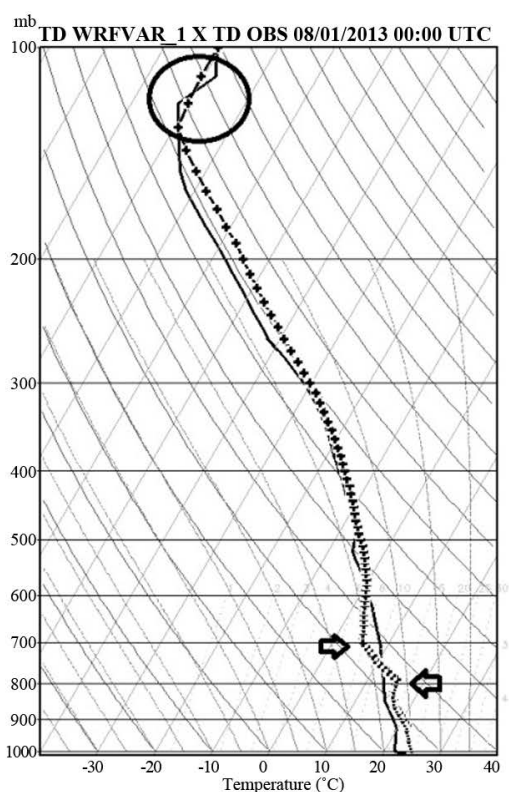

(b)

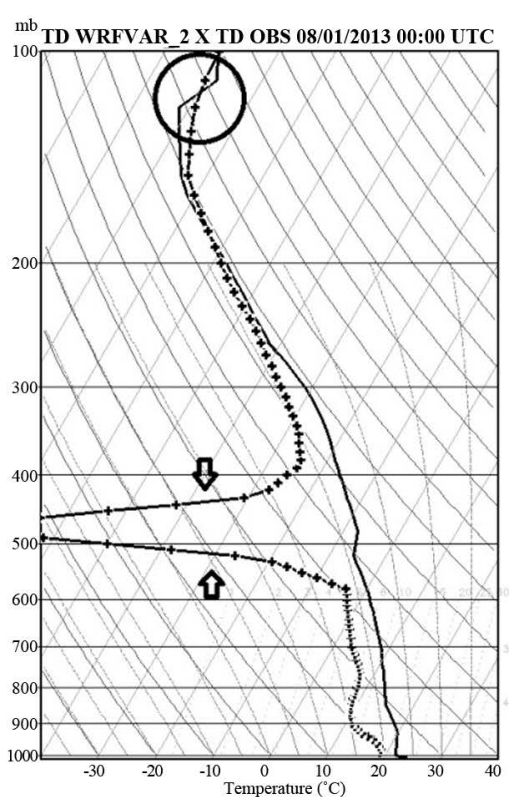

(c)

Figure 15. Dew point temperature vertical profiles for January $8^{\text {th }}$ at 00:00 UTC for Porto Alegre. The black line represents the observed values and the gray line represents the simulated values.
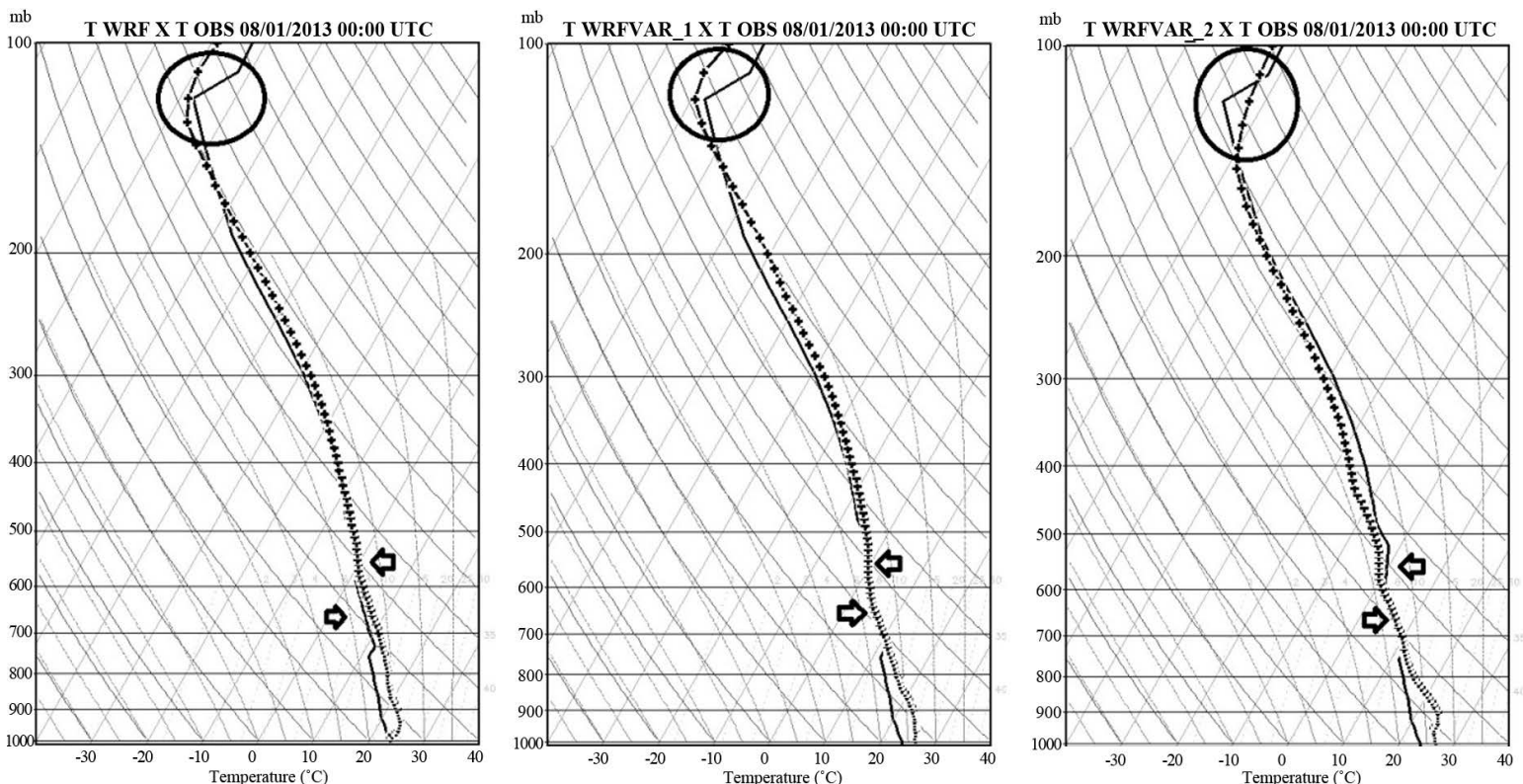

Figure 16. Temperature vertical profiles for January $8^{\text {th }}$ at 00:00 UTC for Porto Alegre. The black line represents the observed values and the gray line represents the simulated values.

data assimilation, WRF case, and this proximity is close to $600 \mathrm{hPa}$ and $500 \mathrm{hPa}$. Although it is possible to note that the observed profile presented, at high levels, heat exchange between the $200 \mathrm{hPa}$ and $100 \mathrm{hPa}$ layers-that compared with the simulated profiles shown in Figures 16(a)-(c) it is clear that it was best represented by the simulation with the data assimilation WRFVAR_1.

\section{Conclusions}

This presentation is restricted to the case of a storm weather condition during the period of January $7^{\text {th }}$ to $9^{\text {th }}$, 
2013. In this period, the accumulated rainfall registered values for Porto Alegre town were very significant. Through the analysis of simulations for the period of 24 hours it was possible to infer that in general, the assimilated data insertion in the rainfall fields shows a positive impact. Also referring to the positioning of the convective cells, it is very clear that the technique is effective.

For reflectivity field it was possible to observe that both simulations with data assimilation have presented coherent results to the observed reflectivity. With respect to the vertical profiles for the temperature and the dew point temperature, it can be inferred that both variables have been well represented on three simulations. It is pointed out that some characteristics of the vertical profiles highlight the use of the data assimilation for showing better results.

\section{References}

[1] Smith, W.L. (1996) Atmospheric Sounding from Satellites-False Expectation or the Key to Improved Weather Prediction? Quarterly Journal of the Royal Meteorological Society, 117, 267-297.

[2] Joiner, J. and da Silva, A.M. (1998) Efficient Methods to Assimilate Remotely Sensed Data Based on Information Content. Quarterly Journal of the Royal Meteorological Society, 124, 1669-1694. http://dx.doi.org/10.1002/qi.49712454915

[3] Anderson, J.L. and Anderson, S.L. (1994) A Monte Carlo Implementation of the Nonlinear Filtering Problem to Produce Ensemble Assimilations and Forecasts. Monthly Weather Review, 127, 2741-2758. http://dx.doi.org/10.1175/1520-0493(1999)127<2741:AMCIOT>2.0.CO;2

[4] Rabier, F., Klinker, E., Courtier, P. and Hollingsworth, A. (1996) Sensitivity of Forecast Errors to Initial Conditions. Quarterly Journal of the Royal Meteorological Society, 122, 121-150. http://dx.doi.org/10.1002/qi.49712252906

[5] Lorenc, A.C., Ballard, S.P., Bell, R.S., Ingleby, N.B., Andrews, P.L.F., Barker, D.M., Bray, J.R., Clayton, A.M., Dalby, T., Li, D., Payne, T.J. and Saunders, F.W. (2000) The Met. Office Global Three-Dimensional Variational Data Assimilation Scheme. Quarterly Journal of the Royal Meteorological Society, 126, 2991-3012. http://dx.doi.org/10.1002/qj.49712657002

[6] Macedo, L.R., Tuchtenhagen, P.N. and Yamasaki, Y. (2012) Avaliações De Prognósticos WRF Com Distintas Parametrizações. CongreMet IX, Mendoza. Anais do IX CongreMet, Argentina.

[7] Silva, G.L., Da Silva, A.S. and Yamasaki, Y. (2012) Validação da Assimilação de Dados na Inferência da Refletividade de um Radar com o Sistema MM5. Revista Brasileira de Meteorologia, 27, 75-84. http://dx.doi.org/10.1590/S0102-77862012000100008

[8] Lorenc, A.C. (1986) Analysis Methods for Numerical Weather Prediction. Quarterly Journal of Royal Meteorology Society, 112, 1177-1194. http://dx.doi.org/10.1002/qi.49711247414

[9] Dudhia, J. (2005) The Weather Research and Forecast Model Version 2.0: Physics Update. WRF/MM5 User’s Workshop. http://www2.mmm.ucar.edu/mm5/workshop/ws04/Session1/Dudhia.Jimy2.pdf

[10] Parrish, D.F. and Derber, J.C. (1992) The National Meteorological Center’s Statistical Spectral Interpolation Analysis System. Monthly Weather Review, 109, 1747-1763. http://dx.doi.org/10.1175/1520-0493(1992)120<1747:TNMCSS>2.0.CO;2

[11] Skamarock, W.C., Klemp, J.B., Dudhia, J., Gill, D.O., Barker, D.M., Duda, M.G., Huang, X., Wang, W. and Powers, J.G. (2008) A Description of the Advanced Research WRF Version 3. NCAR/TN 475+STR Technical Note, UCAR.

[12] Courant, R., Friedrichs, K. and Lewy, H. (1956) On the Partial Difference Equation of Mathematical Physics. AEC Computing Facility, Institute of Mathematical Sciences, New York University, New York.

[13] Fierro, A.O., Mansell, E.R., Ziegler, C. and MacGorman, D.R. (2012) Application of a Lightning Data Assimilation Technique in the WRF-ARW Model at Cloud-Resolving Scales for the Tornado Outbreak of 24 May 2011. Monthly Weather Review, 140, 2609-2627. http://dx.doi.org/10.1175/MWR-D-11-00299.1 